\title{
KOMBINASI PIJAT OKSITOSIN, TEKNIK MARMET, PEMBERIAN EKSTRAK DAUN KATUK TERHADAP PRODUKSI AIR SUSU IBU
}

\section{COMBINATION OF OXYTOCIN MASSAGE, MARMET ENGINEERING, GIVING COTTON LEAF EXTRACT ON PRODUCTION BREAST MILK}

\author{
Hafni Van Gobel, Suwarly Mobiliu \\ Program Studi Keperawatan \\ Politeknik Kesehatan Gorontalo \\ labtech.muhammadtaufiq01@gmail.com
}

\begin{abstract}
Abstrak
Jenis penelitian yang digunakan adalah true eksperimen dengan rancangan penelitian with control group design. Penelitian ini dilaksanakan di wilayah kerja RSUD MM. Dunda Limboto pada bulan Juli sampai dengan Oktober 2018. Variabel dalam penelitian ini yaitu pijat oksitosin, teknik marmet dan pemberian tablet pelancar ASI, variabel terikat adalah peningkatan produksi ASI. Besar sampel 60 orang ibu post partum, terdiri dari 30 orang kelompok yang mendapat perlakuan dan 30 orang sebagai kelompok kontrol. Hasil uji statistik kruskall-wallis menunjukkan perbedaan signifikan antara kedua kelompok sampel $(\mathrm{p}=0.000)$. Lebih lanjut, hasil uji statistik mann-whitney juga menunjukkan perbedaan yang signifikan antara kedua kelompok sebelum dan sesudah perlakuan $(\mathrm{p}=0.000$ dan $\mathrm{p}=0.156)$. Kombinasi pijat oksitosin, teknik marmet dan pemberian tablet ekstrak daun katuk efektif meningkatkan produksi ASI ibu post partum primigravida di wilayah kerja RSUD MM. Dunda Limboto.
\end{abstract}

Kata kunci. ASI Eksklusif, Pijat Oksitosin, Teknik Marmet, Ekstrak Daun Katuk.

\begin{abstract}
The type of research used is a true experiment with a research design with control group design. This research was carried out in the working area of MM Hospital. Dunda Limboto from July to October 2018. Variables in this study were oxytocin massage, marmet technique and administration of ASI smoothening tablets, the dependent variable was increased milk production. The sample size of 60 postpartum mothers consisted of 30 treated groups and 30 as control groups. The results of the cruciferous-Wallis statistical test showed a significant difference between the two groups of samples $(p=0.000)$. Furthermore, the results of the Mann-Whitney statistical test also showed significant differences between the two groups before and after treatment $(p=0.000$ and $p=0.156)$. The combination of oxytocin massage, guinea pig technique and administration of katuk leaf extract tablets effectively increased the milk production of primigravida postpartum mothers in the working area of MM Hospital. Dunda Limboto.
\end{abstract}

Keywords. Exclusive Breast Milk, Oxytocin Massage, Marmet Technique, Katuk Leaf Extract. 


\section{Pendahuluan}

Organisasi Kesehatan Dunia (WHO) merekomendasikan agar bayi baru lahir mendapat ASI eksklusif selama enam bulan sebab ASI adalah nutrisi alamiah terbaik bagi bayi dengan kandungan gizi paling sesuai untuk pertumbuhan optimal (Hegar, 2008). Pemberian ASI Eksklusif pada bayi merupakan cara terbaik bagi peningkatan kualitas Sumber Daya Manusia (SDM) sejak dini. Di Indonesia, Departemen Kesehatan Republik Indonesia melalui program perbaikan gizi masyarakat telah menargetkan cakupan ASI eksklusif 6 bulan sebesar $80 \%$. Namun demikian, angka ini sangat sulit untuk dicapai, bahkan tren prevalensi ASI eksklusif dari tahun ke tahun terus menurun. Hal tersebut sangat memprihatinkan mengingat ASI eksklusif sangat penting bagi tumbuh kembang bayi. Data Riset Kesehatan Dasar (Riskedas) 2013 menunjukkan cakupan ASI di Indonesia hanya 42 persen. Angka ini jelas berada di bawah target WHO yang mewajibkan cakupan ASI hingga 50 persen. Angka kelahiran di Indonesia mencapai 4,7 juta per tahun, maka bayi yang memperoleh ASI selama enam bulan hingga dua tahun, tidak mencapai dua juta jiwa. Angka ini menandakan hanya sedikit anak Indonesia yang memperoleh kecukupan nutrisi dari ASI. Padahal ASI berperan penting dalam proses tumbuh kembang fisik dan mental anak dengan dampak jangka panjangnya.

Hasil riset yang dilakukan di Denmark pada 3.203 anak. Anak yang menyusu ASI kurang dari satu bulan memiliki tingkat IQ lebih rendah dibanding yang memperoleh ASI hingga 7-9 bulan. ASI juga meningkatkan daya tahan tubuh anak. Berdasarkan riset yang dimuat dalam buletin Lancet pada tahun 2013 diungkapkan, pemberian ASI bisa menekan kematian balita hingga 13 persen (Widiani, 2013).

Salah satu penyebab produksi ASI meningkat atau menurun adalah adanya stimulasi pada kelenjar payudara terutama pada minggu pertama laktasi. Oleh sebab

itu ibu dianjurkan menyusui dini agar isapan bayi segera menstimulasi hipofisis anterior untuk memproduksi hormone prolactin dan hipofisis posterior untuk memproduksi hormon oksitosin (Proverawati \& Rahmawati, 2010)

Ketidakmampuan dalam mencukupi produksi ASI dapat dicegah dengan berbagai cara antara lain, mengajarkan metode yang sesuai untuk memperlancar pengeluaran ASI maupun meningkatkan produksi ASI seperti meningkatkan kualitas makanan yang berpengaruh secara langsung pada produksi air susu, misalnya sayuran hijau, daun katuk, daun pepaya dan sebagainya. Selain itu cara lain yang dapat digunakan untuk merangsang produksi adalah dengan melakukan tindakan yang dapat merangsang pengeluaran dan produksi ASI seperti melakukan pijat oksitosin dan Teknik marmet. Teknik marmet memberikan efek relaks dan juga mengaktifkan kembali reflex keluarnya air susu/milk ejection reflex (MER) (Martha \& William, 2007). Sedangkan pijat oksitosin adalah tindakan yang dilakukan pada ibu menyusui berupa back massage pada punggung ibu untuk meningkatkan pengeluaran hormone oksitosin (Suhermi, 2009). Dan untuk pemberian tablet pelancar ASI secara bersamaan dengan kedua teknik diatas dimungkinkan untuk lebih memastikan produksi ASI lebih meningkat

\section{Metode}

Jenis penelitian yang digunakan adalah true eksperimen dengan rancangan penelitian with control group design. Penelitian ini dilaksanakan di wilayah kerja RSUD MM. Dunda Limboto pada bulan Juli sampai dengan Oktober 2018. Variabel dalam penelitian ini yaitu variabel bebas adalah pijat oksitosin, teknik marmet dan pemberian tablet pelancar ASI, variabel terikat adalah peningkatan produksi ASI. Produksi ASI diukur menggunakan indikator utama yaitu BB bayi yang ditimbang pada hari ke 1 , ke 7 dan ke 14 (BB bayi sesuai dengan BB lahir atau naik). Indikator lain yaitu frekuensi BAK 6-8 kali perhari, frekuensi menyusui $8-12 x$ perhari bayi tidak rewel dan tidur nyenyak 2-3 jam setelah menyusu. Menggunakan skala ratio, alat ukur timbangan bayi, breast pump, cara pengukuran lewat observasi dan kuisioner. Pijat oksitosin dilakukan dengan cara 
memijat pada bagian punggung ibu post partum hari ke 1-3 pada sisi tulang belakang (vertebra) sampai ke tulang belikat (costa 5-6), sesuai standar prosedur pijat oksitosin. Teknik marmet dilakukan pada ibu post partum hari ke 1-3 dengan cara kombinasi yakni memerah dan memijat, menggunakan Standar Prosedur Teknik Marmet. Pemberian tablet ekstrak daun katuk dilakukan pada ibu post partum hari ke 1-3 dengan cara diminum dengan dosis 3 x $300 \mathrm{mg}$ sehari, dengan lama pemberian selama 2 minggu.

Populasi dalam penelitian ini adalah seluruh ibu post partum yang melahirkan secara normal di wilayah kerja RSUD MM. Dunda Limboto pada bulan Juli sampai dengan Oktober 2018 dengan besar sampel 60 orang, terdiri dari 30 orang kelompok yang mendapat perlakuan dan 30 orang sebagai kelompok kontrol. Teknik sampling yang digunakan dalam penelitian ini adalah menggunakan consecutive sampling, dengan menetapkan subjek yang memenuhi kriteria pemilihan sampai kurun waktu tertentu sehingga jumlah sample yang diperlukan terpenuhi (Nursalam ,2011).

Pengolahan data dilakukan dengan langkah-langkah sebagai berikut: penyuntingan data, membuat lembar kode, memberikan skoring, memasukan data kedalam program pengolah data statistik (SPSS), melakukan tabulasi, pembersihan data, dan analisis data berupa analisis univariat dan bivariat menggunakan kruskall-wallis dan uji lanjut mann-whitney.

Lembar persetujuan diberikan kepada responden dengan tujuan agar responden mengetahui maksud dan tujuan penelitian. Untuk menjaga kerahasiaan identitas responden peneliti tidak mencantumkan nama responden dalam pengumpulan data. Semua informasi yang telah dikumpulkan dijamin kerahasiaannya oleh peneliti, hanya kelompok data tertentu yang akan dilaporkan pada hasil riset.

\section{Hasil}

Data hasil penelitian dikelompokkan dalam distribusi frekuensi responden dan hasil uji statistik data volume ASI kelompok Control dan kelompok treatment. Volume ASI kelompok treatment sebelum dilakukan perlakuan dicatat terlebih dahulu. Setelah tratment dilakukan, maka volume ASI sesudah treatment kembali diukur. Ada tidaknya perbedaan volume ASI yang signifikan dari ketiga kelompok diatas kemudian ditentukan menggunakan uji statistik dengan bantuan software statistik. Data distribusi frekuensi responden pada penelitian ini terbagi dalam beberapa kelompok sebagai berikut.

\section{Berdasarkan Kelompok Usia}

Kelompok usia responden paling banyak adalah responden usia 16-25 tahun (31 responden / 51,7\%) dan paling sedikit adalah responden usia 36-45 tahun (10 responden / 16,7\%).

\section{Berdasarkan Pendidikan}

Kualifikasi pendidikan dengan jumlah tertinggi adalah respondek kualifikasi pendidikan SMA (21 responden / 35\%) dan terendah adalah responden yang tidak mengenyam pendidikan formal (2 responden $/ 3,3 \%$ ).

\section{Berdasarkan Pekerjaan}

Jumlah responden yang bekerja sebagai IRT adalah yang tertinggi (36 responden / 60\%) sedangkan responden yang bekerja sebagai PNS memiliki persentase terendah (1 responden / 1,7\%).

\section{Berdasarkan Status Persalinan}

Terdapat delapan responden $(13,3 \%)$ pernah mengalami abortus sekali dan satu responden $(1,7 \%)$ pernah mengalami dua kali abortus.

\section{Berdasarkan Jenis Persalinan}

Diketahui bahwa 35 responden (58.3\%) bersalin normal (Pervaginam) sedangkan 25 responden $(41,7 \%)$ melalui persalinan secara sectio/caesaria.

Untuk menentukan uji statistik yang tepat, perlu diketahui jenis sebaran atau distribusi data volume ASI dari kelompok control dan kelompok treatment.

\section{Uji Normalitas}

Dari data uji normalitas diatas, diketahui bahwa nilai signifikan kelompok control adalah 0,000 (K-S) dan 0,001 (S$\mathrm{W})$, kelompok treatment (sebelum) adalah 
0,000 (K-S) dan 0,000 (S-W) dan kelompok treatment (sesudah) adalah 0,198 (K-S) dan 0,034 (S-W). Data nilai signifikan ketiga kelompok diatas $<0,05$ sehingga dapat disimpulkan bahwa data volume ASI ketiga kelompok tidak berdistribusi normal, maka uji statistik yang harus digunakan untuk menilai ada tidaknya perbedaan signifikan antara data volume ASI ketiga kelompok tersebut adalah uji statistik non-parametrik. Dalam hal ini, peneliti menggunakan uji statistik Kruskal-Wallis serta uji lanjut Mann-Whitney.

\section{Uji statistik non parametrik kruskall-wallis}

Uji statistik non parametrik kruskallwallis dilakukan untuk mengetahui ada tidaknya perbedaan signifikan data volume ASI dari ketiga kelompok yang menjadi subjek penelitian ini. Diketahui bahwa nilai signifikan ketiga kelompok diatas adalah 0,000 . Data tersebut menunjukkan nilai signifikan uji <0,05, yang berarti bahwa terdapat perbedaan yang signifikan antara ketiga kelompok uji diatas. Hasil uji statistik Kruskall-Wallis hanya dapat menjabarkan ada tidaknya perbedaan yang signifikan antara ketiga kelompok uji diatas namun tidak dapat dengan spesifik menunjukkan pasangan kelompok mana saja yang memiliki perbedaan nilai yang signifikan. Karena keterbatasan tersebut, maka perlu dilakukan uji lanjut menggunakan uji statistik Mann-Whitney untuk mengetahui pasangan kelompok mana saja yang meiliki perbedaan nilai yang signifikan.

\section{Uji Mann-Whitney}

Uji Mann-Whitney dilakukan untuk mengetahui pasangan kelompok mana saja yang memiliki perbedaan nilai yang signifikan. Dari data Uji Mann-Whitney menunjukkan nilai signifikan pasangan kelompok Control-Sesudah Treatment adalah 0,000 . Nilai signifikan pasangan kelompok Control-Sesudah Treatment $<0,05$, maka dapat disimpulkan bahwa tidak terdapat perbedaan volume ASI yang signifikan antara kelompok control dan kelompok treatment (Sesudah).

\section{Uji Mann-Whitney Pasangan Kelompok Sebelum Treatment-Sesudah Treatment}

Data Uji Mann-Whitney pasangan kelompok sebelum treatment-sesudah treatment, menunjukkan nilai signifikan pasangan kelompok Sebelum TreatmentSesudah Treatment adalah 0,156. Nilai signifikan pasangan kelompok Sebelum Treatment-Sesudah Treatment $>0,05$, maka dapat disimpulkan bahwa terdapat perbedaan volume ASI yang signifikan antara kelompok treatment (sebelum) dan kelompok treatment (Sesudah).

\section{Pembahasan}

Pada penelitian ini, peneliti mencoba mengkombinasikan tiga perlakuan pada tiap responden untuk melihat sejauh mana efektifitas metode ini untuk menghasilkan ASI. Berdasarkan hasil uji statistik yang telah dilakukan, terdapat perbedaan volume ASI yang cukup signifikan antara kelompok sebelum perlakuan dan kelompok sesudah perlakuan. Hal ini sejalan dengan beberapa penelitian terdahulu yang telah dilakukan. Lebih lanjut, tentunya hal ini akan sangat bermanfaat bagi Ibu menyusui yang ingin memberikan ASI eksklusif kepada buah hatinya.

Hasil penelitian Jones dkk tahun 2001 yang berjudul "A Randomised Controlled Trial to Compare Methods of Milk Expression After Preterm Delivery" menunjukkan Ibu yang memompa payudaranya secara teratur lebih lancar produksi ASI-nya daripada Ibu yang tidak teratur memompa payudaranya. Kombinasi memompa dan memijat payudara lebuh efektif dalam memproduksi ASI dan dianjurkan pada Ibu yang bayinya sakit atau lahir premature. Hasil penelitian tersebut sejalan dengan hasil penelitian yang telah dilakukan oleh Desmayanti (2008) dengan judul "Efektifitas Kombinasi Areolla Massage dengan Rolling Massage terhadap Pengeluaran ASI secara Dini pada Ibu Post SC di Puskesmas Pamulang dan Cikupa Banten". Hasil penelitian tersebut menunjukkan Ibu yang diberi intervensi kombinasi Areolla Massage dengan Rolling Massage efektif dalam menstimulus hipofis anterior dan posterior mensekresi hormone prolactin dan oksitosin di awal menyusui. 
Hal tersebut menunjukkan bahwa kombinasi treatment akan lebih efektif dalam hal memperlancar keluarnya ASI.

Menurut Dazel (2010), dengan melakukan teknik marmet dapat membantu kunci reflek pengeluaran ASI yang efektif dalam hari-hari pertama menyusui, karena tebalnya konsistensi kolostrum dan ketika susu matang diproduksi. Teknik marmet mengembangkan metode pijat dan stimulasi untuk membantu kunci reflek pengeluaran ASI.

Dalam prakteknya, terdapat beberapa hal yang mempengaruhi jumlah produksi ASI salah satunya perawatan payudara. Perawatan yang baik dan tepat di awal menyusui dapat merangsang payudara memproduksi ASI lebih dini dengan volume yang banyak. Produksi ASI juga dipengaruhi oleh frekuensi menyusui, dimana semakin sering seorang Ibu menyusui maka produksi ASI akan semakin meningkat.

Realita di lapangan saat ini menunjukkan bahwa produksi dan ejeksi ASI yang cenderung minim pada hari awal melahirkan menjadi salah satu kendala dalam proses pemberian ASI secara dini. Tidak keluarnya produksi ASI pada harihari pertama pasca kelahiran mengakibatkan banyak Ibu beralih untuk memberikan susu formula kepada bayinya. Bila prelactal feeding telah diberikan kepada bayi, maka ASI akan terbentuk lebih lambat karena tidak ada rangsangan putting payudara dari hisapan bayi. Hal ini menyebabkan bayi enggan menyusu sehingga hipofisis tidak terstimulus dan berimbas pada tidak diproduksinya ASI. Sejalan dengan pernyataan Prasetyono (2012) dalam bukunya berjudul "Buku Pintar ASI Eksklusif" yang menyatakan bahwa segera setelah dilahirkan, bayi harus disusukan kepada Ibunya, tindakan ini bukan dimaksudkan untuk memberi nutrisi, tetapi agar bayi belajar menyusui atau menghisap putting susu payudara Ibu, serta mendukung produksi ASI. Gerakan refleks bayi yang baru lahir yang emnghisap puting payudara Ibu akan mencapai puncaknya pada 20-30 menit setelah kelahiran bayi. Jika Ibu terlambat menyusui bayinya, maka refleks itu akan berkurang.
Peran tenaga kesehatan dalam memberikan dukungan psikologis tidak bisa dilepaskan dari usaha Ibu dalam meningkatkan produksi ASI. Pemberian nasihat dan penyuluhan tentang ASI perlu diberikan terutama pada Ibu yang baru pertama kali mempunyai anak, dan belum mengetahui cara cara menyusu yang benar, begitu pula dengan pemberian intervensi tentang perawatan payudara, dan pemberian suplemen pelancar ASI, sehingga masalah menyusui yang muncul pada hari-hari pertama menyusui seperti produksi ASI sedikit, ASI tidak lancar dan ASI tidak keluar dapat diatasi.

\section{Kesimpulan dan Saran}

Kombinasi pijat oksitosin, teknik marmet dan pemberian tablet ekstrak daun katuk efektif meningkatkan produksi ASI ibu post partum primigravida di wilayah kerja RSUD MM. Dunda Limboto.

Peneliti menekankan perlunya mengupayakan pelatihan manajemen laktasi, khususnya tentang pijat oksitosin, teknik marmet dan pemberian tablet pelancar ASI pada petugas kesehatan agar lebih terampil dan terlatih dalam memberikan asuhan kebidanan guna meningkatkan produksi ASI pada ibu postpartum. Perlu dilakukan penelitian terkait kadar oksitosin yang diekskresikan setelah treatment dilakukan.

\section{Daftar Pustaka}

Desmayanti, 2008. Efektifitas Kombinasi Areolla Massage dengan Rolling Massage terhadap Pengeluaran ASI secara Dini pada Ibu Post SC di Puskesmas Pamulang dan Cikupa Banten. Universitas Islam Bandung

Jones. E, dkk., 2001. A Randomised Controlled Trial to Compare Methods of Milk Expression After Preterm Delivery. Journal List Arch Dis Child Fetal Neonatal Ed 2001;85; F91-F95

Hegar, B, dkk. 2008. Bedah ASI Kajian dari Berbagai Sudut Pandang Ilmiah. Ikatan Dokter Anak Indonesia Balai Penerbit FKUI pp: Jakarta:

Nursalam. 2011. Konsep dan Penerapan Metodologi Penelitian Ilmu 
Keperawatan. Salemba Medika:

Jakarta

Prasetyono, DS. 2012. Buku Pintar ASI

Eksklusif. Diva Press, Jogjakarta

Proverawati, A. \& Rahmawati, E. (2010).

Kapita Selekta ASI dan Menyusui.

Nuha Medika: Yogyakarta.

Suherni, dkk. 2009. Perawatan Masa Nifas.

Fitramaya: Jakarta.

post partum, Prodi D3 Kebidanan Stikes

Estu Utomo Boyolali

Widiastuti, A dkk. 2015. Pengaruh Teknik

Marmet terhadap Kelancaran Air Susu

Ibu dan Kenaikan Berat Badan Bayi,

Program Studi Keperawatan

Politeknik Kesehatan Kementerian

Kesehatan Semarang 